Subscriber access provided by UNIV OF DURHAM

\title{
Article
}

\section{Novel electrochemical paper-based immunocapture assay for the quantitative determination of ethinylestradiol in water samples}

\author{
María L. Scala-Benuzzi, Julio Raba, Galo J. A. A. Soler-Illia, Rudolf J. Schneider, and Germán A. Messina
}

Anal. Chem., Just Accepted Manuscript • DOI: 10.1021/acs.analchem.8b00028 • Publication Date (Web): 23 Feb 2018

Downloaded from http://pubs.acs.org on February 24, 2018

\section{Just Accepted}

"Just Accepted" manuscripts have been peer-reviewed and accepted for publication. They are posted online prior to technical editing, formatting for publication and author proofing. The American Chemical Society provides "Just Accepted" as a service to the research community to expedite the dissemination of scientific material as soon as possible after acceptance. "Just Accepted" manuscripts appear in full in PDF format accompanied by an HTML abstract. "Just Accepted" manuscripts have been fully peer reviewed, but should not be considered the official version of record. They are citable by the Digital Object Identifier (DOI®). "Just Accepted" is an optional service offered to authors. Therefore, the "Just Accepted" Web site may not include all articles that will be published in the journal. After a manuscript is technically edited and formatted, it will be removed from the "Just Accepted" Web site and published as an ASAP article. Note that technical editing may introduce minor changes to the manuscript text and/or graphics which could affect content, and all legal disclaimers and ethical guidelines that apply to the journal pertain. ACS cannot be held responsible for errors or consequences arising from the use of information contained in these "Just Accepted" manuscripts. 
The presence of new pollutants in wastewater and aquatic environments has received considerable attention during the last years. "Emerging pollutants" are new products or chemicals without regulatory status and whose effects on the environment and human health are so far mostly unknown. ${ }^{1,2}$

Among the emerging pollutants, several pharmaceutical products are currently found in water samples. The most widely used oral contraceptive formulations contain ethinyl estradiol (EE2), a synthetic hormone derived of the natural estrogen estradiol. In contrast to the last one, EE2 is resistant to degradation by liver; therefore a great amount of EE2 and its derivatives are introduced into the environment. EE2 is considered as an endocrine disrupting compound (EDC) ${ }^{3}$, having negative impact on the reproductive system of wild animals. ${ }^{4,5}$ In addition, some studies report that EE2 might have important consequences on human health., ${ }^{6,7}$

For this reason, the quantitative determination of EE2 in natural water samples has become an important challenge. Due to its low concentration in water, in the range of $n g / L^{8}$, common methods include a previous step of separation and pre-concentration, such as solid-phase extraction and determination by high-performance liquid chromatography, coupled with mass spectrometric detection. ${ }^{9,10}$ These techniques allow to develop sensitive methods, but they have some limitations such as being time-consuming, and requiring both large volumes of sample and expensive equipment, precluding fast, on site analysis. Alternatively, an enzyme immunoassay has been developed for the determination of EE2 in environmental samples. ${ }^{11}$ This test shows high selectivity due to the specificity of the antigen-antibody recognition, but it has the disadvantage of having a long total assay time. In addition, electrochemical immunosensors, which combine the features of electrochemical detection with the use of magnetic nanoparticles, have been applied to environmental samples. ${ }^{12}$ These methodologies need however highly skilled technicians, making them difficult for application in routine work, particularly in fast assessment of pollutants on-site. 
Since Martinez et al. ${ }^{13}$ described a method to obtain patterned papers, paper-based analytical devices (PADs) have become a rising alternative in the field of lab-on-chip. PADs represent a promising technology for the development of new analytical biosensors ${ }^{14,15}$, because they open the possibility of combining highly sensitive methods and complex functions in low-cost devices, with rapid and simple fabrication. ${ }^{16}$ The PADs have been applied in different fields, such as public health, ${ }^{17,18}$ food quality control ${ }^{19}$ and environmental monitoring, ${ }^{20,}{ }^{21}$ among others. Dungchai et al. reported for the first time a microfluidic PAD with electrochemical detection using screen-printed carbon ${ }^{22}$ for the determination of glucose, lactate, and uric acid in biological samples. The use of PADs for separation and pre-concentration of analytes from complex samples arises as one interesting approach towards the development of new portable analytical devices. This application turns them into an interesting strategy when the determination of low levels of several compounds is desired.

The paper surface is an excellent matrix for easy biomolecule immobilization; this advantage can be exploited in the development of biosensors. For example, Cheng et al. ${ }^{23}$ propose a paper-based ELISA which presents several advantages over conventional ELISA. Antibodies can be covalently bonded onto the paper surface by a chemical attack on the cellu$\operatorname{lose}^{16}$ or by plasma treatment. ${ }^{24}$ Consequently, an inexpensive platform for immunocapture can be obtained. Also, the paper surface offers a remarkable matrix which can be easily modified with nanomaterials, generating new surfaces with different characteristics. Silica nanoparticles (SNs) have been previously used as support nanomaterial in microfluidic devices because they increase the surface for immobilization of biomolecules, permitting to enhance their incorporation into devices, therefore leading to signal enhancement. ${ }^{25}$ Moreover, SNs show good monodispersity, stability and they can be easily functionalized. These features make them an excellent option for PADs surface modifications. ${ }^{26,27}$

An interesting approach for sensing EE2 is based on the electrochemical behavior of this synthetic hormone. ${ }^{28-30}$ This feature allows to combine the specificity of the antigenantibody recognition with electrochemical techniques for monitoring its concentration in environmental samples. These allow for high sensitivity, fast detection and low-cost equipment. In addition, electrochemical signaling could be improved by employing nanomaterials, such as noble metal nanoparticles, nanostructured metal oxides or carbon-based nanomaterials. $^{31,32}$ These latter ones are the most widely used in electrode surface modifications due to their inherent conduction properties. Besides, they allows to obtain an increased active surface and consequently improved sensitivity and lower detection limits. ${ }^{33}$ Particularly, graphene has emerged as an interesting nanomaterial due its unique properties, that include high surface area, high mechanical strength, low cost, ease of processing, safety and high electric conductivity. ${ }^{34,35}$ Due to these advantages, graphene is an excellent choice of nanomaterial for electrochemical biosensing. ${ }^{36,37}$ Modified electrodes could be coupled to different reaction platforms, PADs being one of them. Moreover, paper has the advantage of being biodegradable, biocompatible, renewable and readily modifyable. $^{38}$

The goal of this work was to develop a novel paper-based immunocapture assay for quantitative determination of EE2 in water samples. The method is based on the use of paper mi- crozones modified with SNs and anti-EE2 specific antibodies for the capture, pre-concentration and determination of EE2. The paper microzones were to be read-out by transfer to a screen-printed carbon electrode (SPCE) modified with electrochemically reduced graphene (RG). Recovered EE2 was electrochemically detected by Osteryoung square wave voltammetry (OSWV) where the obtained oxidation current was proportional to the EE2 concentration in the sample. This method could be a novel and efficient analytical tool for the determination of any pollutant in water samples, an answer to the growing need for inexpensive, sensitive, rapid and portable detection systems. In addition, it can be proposed for separating sampling from analysis.

\section{EXPERIMENTAL SECTION}

Reagents and solutions. All reagents were of analytical or biochemical grade. Ethinylestradiol and Whatman paper \#1 (WCP\#1) were purchased from Sigma Chemical Co., St. Louis, Missouri, USA. Polyclonal rabbit anti-EE2 Ab (SA 2150) ${ }^{39}$ was supplied by BAM Federal Institute for Materials Research and Testing, Berlin, Germany. Glutaraldehyde (25\% aqueous solution), hydrogen peroxide $\left(\mathrm{H}_{2} \mathrm{O}_{2}\right)$ and sulfuric acid were purchased from Merck, Darmstadt, Germany. 3-aminopropyl functionalized silica (50 $\mathrm{nm}$ particle size), graphite and humic acid were purchased from Sigma Aldrich, Argentina. All other reagents and solvents of analytical grade were used without further purification; the presence of EE2 was not detected in the working range. All solutions were prepared with ultra-high quality water obtained from a Barnstead Easy pure RF compact ultra-pure water system. The river water samples were collected from four rivers of San Luis State, Argentina (Potrero de los Funes, El Trapiche, El Volcán and San Luis rivers).

Instrumentation. Electrochemical measurements were performed using a BAS 100B (electrochemical analyzer Bioanalytical Systems West Lafayette, IN, USA). All the electrochemical measurements were performed using screen-printed carbon electrodes (SPCE) (PalmSens). The paper microzones were printed using a ColorQube 8570 wax printer. The oxidation of the paper surface was carried out by an oxygen plasma cleaner (Plasma Technology PLAB SE80 plasma cleaner).

The morphology of SNs immobilized on paper microzones and graphene immobilized over working electrodes were studied by a LEO 1450VP scanning electron microscope (SEM). The analysis of the elemental composition of modified surfaces was made using energy-dispersive X-ray spectroscopy (EDS) with a LEO 1450VP scanning electron microscope. The improvement of the signal by using $\mathrm{SNs}$ in the paper modification was characterized through laser-induced fluorescence (LIF) using a SVM340TM synchronized video microscope (LabSmith).

Graphene synthesis. Graphene oxide (GO) was synthesized using a modified Hummers method ${ }^{40}$ with the following modifications. In brief, $48 \mathrm{~mL}$ of concentrated $\mathrm{H}_{2} \mathrm{SO}_{4}$ were added to a mixture of graphite $(1 \mathrm{~g})$ and $\mathrm{NaNO}_{3}(1 \mathrm{~g})$, which was cooled down to $0^{\circ} \mathrm{C}$ in an ice bath. Then, $6 \mathrm{~g}$ of $\mathrm{KMnO}_{4}$ were slowly added maintaining the temperature below $20^{\circ} \mathrm{C}$ and allowed to react for 3 hours with mechanical stirring at $35^{\circ} \mathrm{C}$. Next, $200 \mathrm{~mL}$ of $\mathrm{H}_{2} \mathrm{O}_{2} 3 \%$ were added to the reaction mixture which was stirred for $30 \mathrm{~min}$. The mixture was centrifuged at $3700 \mathrm{rpm}$ for $30 \mathrm{~min}$ and the supernatant was discarded. Then, the remaining solid material was washed and 
centrifuged with bidistilled water until reaching a neutral $\mathrm{pH}$. The colloidal suspension of GO was obtained adding $1 \mathrm{~mL}$ of bidistilled water to $1 \mathrm{mg}$ of the obtained solid. The mixture was kept under ultrasound for $10 \mathrm{~h}$ and finally the suspension of GO was centrifuged at $3700 \mathrm{rpm}$ for $30 \mathrm{~min}$ and the solid was discarded.

Electrode modification with reduced graphene. The working electrode surface was modified with electrochemically reduced GO. Briefly, $5 \mu \mathrm{L}$ of GO solution $\left(0.1 \mathrm{mg} \mathrm{mL}^{-1}\right)$ were dropped on the working electrode surface of the SPCE and the solvent was evaporated under a heating lamp. Then, the GO was electrochemically reduced applying a potential of $-1200 \mathrm{mV}$ for $800 \mathrm{~s}$ in a $0.5 \mathrm{M} \mathrm{NaNO}_{3}$ solution at $\mathrm{pH}$ 4. This potential was selected as optimum following the work of Toh et al. ${ }^{41}$

The modified surface of the working electrode was characterized by SEM and EDS. Also, an electrochemical characterization was carried out monitoring a $\mathrm{Fe}(\mathrm{CN})_{6}{ }^{4-3-}$ solution (1 $\mathrm{mM} \mathrm{K}_{4}\left[\mathrm{Fe}(\mathrm{CN})_{6}\right] / \mathrm{K}_{3}\left[\mathrm{Fe}(\mathrm{CN})_{6}\right]$ in $0.1 \mathrm{M} \mathrm{KCl}(\mathrm{pH} 6.50)$ ) by Cyclic Voltammetry in a potential range from $-300 \mathrm{mV}$ to 600 $\mathrm{mV}$.

Paper microzone fabrication. The paper microzones were designed and drawn using CorelDraw software version 11.0 (Corel) and were printed onto paper surfaces by a ColorQube 8570 wax printer. The microzone design consisted of a circular shape of $7 \mathrm{~mm}$ in diameter. The printed papers were exposed to heat (at approximately $80^{\circ} \mathrm{C}$ for $3 \mathrm{~min}$ ); consequently, the printed wax design permeated through the paper and generated a hydrophobic barrier.

Modification of paper with silica nanoparticles and antiEE2 antibody immobilization. The paper microzones were treated with plasma for 2 minutes to produce aldehyde groups on the exposed surface. After oxidation, $15 \mu \mathrm{L}$ of aminopropyl functionalized SNs $\left(50 \mu \mathrm{L} \mathrm{mL}^{-1}\right)$ were added and left to react at room temperature for $90 \mathrm{~min}$. Then, the papers microzones were washed three times with bidistilled water and were dried with blotting paper to absorb the excess water from the paper microzones. Later, $15 \mu \mathrm{L}$ of glutaraldehyde $\mathrm{pH} 10$ were placed on the microzones and left to react for $90 \mathrm{~min}$ at room temperature. Next, $5 \mu \mathrm{L}$ of anti-EE2 antibodies (1:100 dilution of purified serum) were added and the paper microzones were incubated for $30 \mathrm{~min}$ at room temperature, followed by a washing step with phosphate buffered saline solution (PBS) $(0.01 \mathrm{M} \mathrm{pH} 7.2)$ to remove excess antibody. In order to avoid unspecific binding, the modified paper microzones were blocked with $1 \%$ of bovine serum album (BSA) in PBS. Finally, the paper microzones with SNs and anti-EE2 antibodies covalently immobilized (P-SN-anti-EE2) were washed three times with PBS and were then ready to use.

Modified paper surfaces were characterized by SEM and EDS. In addition, the immobilization in modified paper microzones was studied. In brief, a colorimetric assay was developed using horseradish peroxidase (HRP) to assess the modifications of three different paper microzones: a) unmodified paper, b) paper previously treated with plasma, c) paper previously oxidized with plasma and subsequently modified with SNs. Then, the three paper microzones were subjected to a fluorescence assay evaluated by an LIF detector. HRP in presence of $\mathrm{H}_{2} \mathrm{O}_{2}$ catalyzes the oxidation of 10-acetyl-3,7 dihydroxyphenoxazine (ADHP) to highly fluorescent resorufin, which was measured using an excitation wavelength of 550 $\mathrm{nm}$ an emission at $585 \mathrm{~nm}$ for detection.
Sample preparation. The proposed method was developed for the quantification of EE2 in river water samples. The samples were collected from four rivers of San Luis State, Argentina. Tap water and ultrapure water were used as controls. For EE2 determination by our electrochemical paper-based immunocapture assay, water samples were passed by gravity through filter paper (Whatman) and by vacuum through 934AHTM RTU glass microfiber filters (Whatman), in accordance with Schneider et al. ${ }^{42}$ Finally, the samples were adjusted to $\mathrm{pH} 7$ using $0.1 \mathrm{M}$ phosphate buffer.

Matrix interference. Organic matter is known to interfere with some immunoassays. Therefore, the effect of the natural matrix on the response of the proposed method was evaluated following the procedure of Schneider et $\mathrm{al}^{42}{ }^{42}$ which employs humic acid to simulate organic matter. Different concentrations of humic acid were added to EE2 standard solutions and the response of the proposed method was evaluated.

EE2 determination. In the paper-based immunocapture step, $250 \mathrm{~mL}$ of preconditioned sample solution containing EE2 were placed into a $500 \mathrm{~mL}$ beaker. Then, the P-SN-antiEE2 was added to the sample and mixed for $30 \mathrm{~min}$ by continuous stirring. Subsequently, the P-SN-anti-EE2 was extracted from the sample with laboratory tweezers, washed with PBS and allowed to dry for $2 \mathrm{~min}$. In order to perform EE2 determination, the P-SN-anti-EE2 with the pre-concentrated EE2 was placed over the RG-SPCE and then, $20 \mu \mathrm{L}$ of $\mathrm{H}_{2} \mathrm{SO}_{4} 10$ $\mathrm{mM}$ were added. This solution destabilizes antigen-antibody binding, releasing the EE2 bound in the paper-based immunocapture step. After 2 minutes, the EE2 present in the sample was quantified by OSWV with the following settings: step potential $\mathrm{E}=4 \mathrm{mV}, \mathrm{SW}$ amplitude $=25 \mathrm{mV}$, SW frequency $=15 \mathrm{~Hz}$, samples per point $=256$, potential range $=$ $300-1100 \mathrm{mV}$, sensitivity $=1 \times 10-5 \mathrm{~A} \mathrm{~V}^{-1}$. Fig. 1 shows a schematic representation of the EPIA for the quantitative determination of EE2 in water samples. The obtained current was proportional to the EE2 concentration in the sample. The total assay time required for the EE2 determination by the electrochemical paper-based immunocapture assay was lower than 40 min (Table S-1, supplementary data).

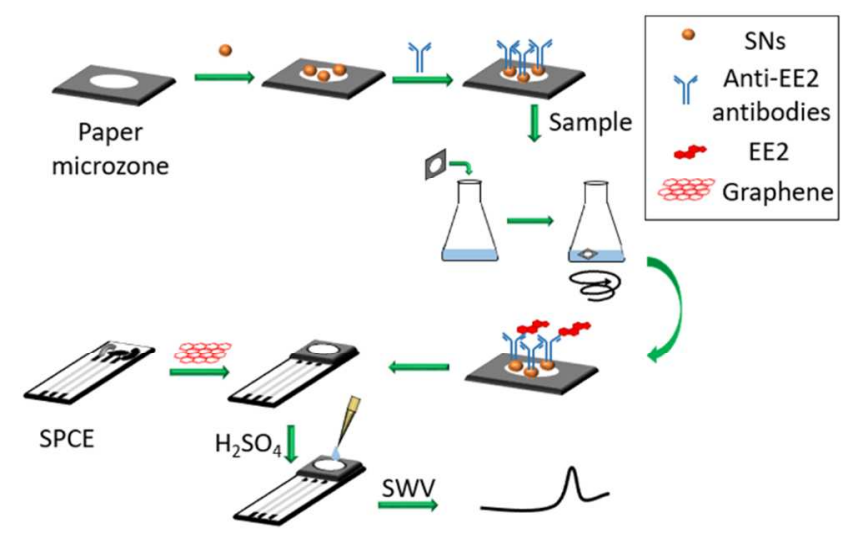

Figure 1. Schematic representation of the electrochemical paperbased immunocapture assay (EPIA) for the quantitative determination of ethinylestradiol (EE2) in water samples. Paper microzones, modified with silica nanoparticles (SNs) and anti-EE2 specific antibodies, were added to river water samples for the capture and pre-concentration of EE2. Then, the paper microzones were placed on the surface of reduced graphene on a screenprinted carbon electrode (SPCE). The bound EE2 was desorbed 
adding onto the paper microzones a diluted solution of sulfuric acid. The recovered EE2 was electrochemically detected by square-wave voltammetry (SWV).

\section{RESULTS AND DISCUSSION}

Characterization of the electrode. The working electrode of the SPCE was modified with synthesized GO and was electrochemically reduced applying a potential of $-1200 \mathrm{mV}$ for $800 \mathrm{~s}$ in a $0.5 \mathrm{M} \mathrm{NaNO}_{3}$ solution at $\mathrm{pH}=4$. The modified electrode surface was characterized by SEM. A homogenous dispersion of GO sheets onto the working electrode surface was observed (Fig. 2a) as well as the graphene agglomeration due to the electrochemical reduction (Fig. 2b). Fig 2c shows the EDS elemental analysis of the modified surfaces. It can be observed that the $\mathrm{C} / \mathrm{O}$ atomic ratio decreases significantly from the GO samples (15.5) as compared to RG (3.5), demonstrating that most of the oxygen-containing functional groups in the GO sheets were eliminated after reduction.
The modified electrodes were electrochemically characterized by Cyclic Voltammetry of $1 \mathrm{mM} \mathrm{Fe}(\mathrm{CN})_{6}^{4-/ 3-}$ solution. Fig. 3a shows well-defined cyclic voltammograms (CV) at the SPCE surface (black line). The red line illustrates the voltammetric response of the redox couple on the RG-SPCE surface. When the GO was electrochemically reduced on the electrode surface, the peak current obtained was larger than the one observed for bare SPCE, indicating that the RG improved the conductivity and increased the active surface area of the electrode. The effect of the scan rate on CVs obtained using the RG-SPCE was also studied (Fig. 3b). The oxidation and reduction current peaks exhibit a linear correlation with the square of scan rate (Fig. 3b inset) in the studied range (20-300 $\left.\mathrm{mV} \mathrm{s}^{-1}\right)$. These results indicate that this is a fast electrochemical and diffusion-controlled process.

\section{(a)}

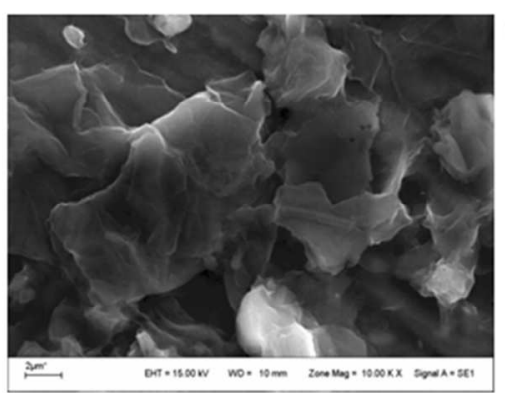

(b)

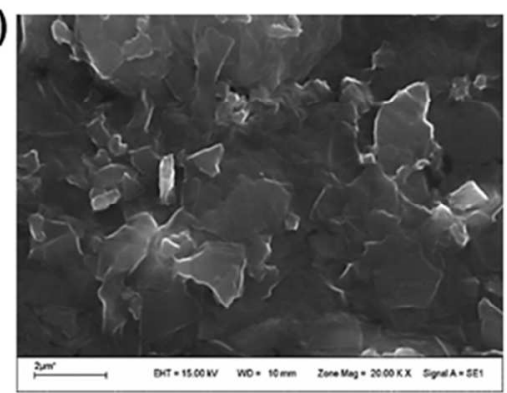

(c)

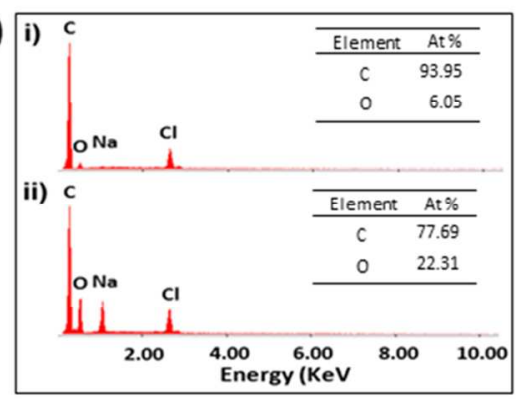

Figure 2. SEM micrographs of GO-SPCE (A) and RG-SPCE (B), and EDS elemental composition of the GO-SPCE surface (C, i) and the electrochemically reduced variant RG-SPCE $(\mathrm{C}$, ii).

(a)

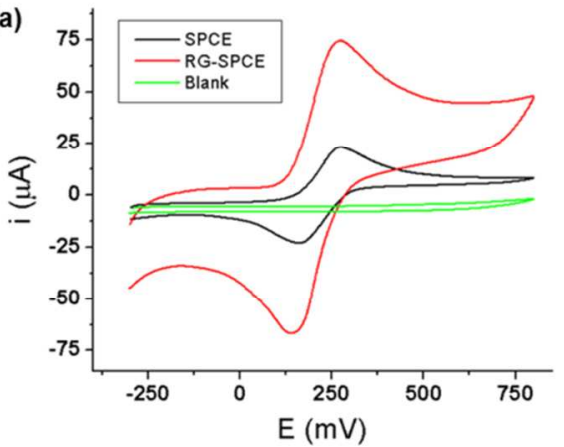

(b)

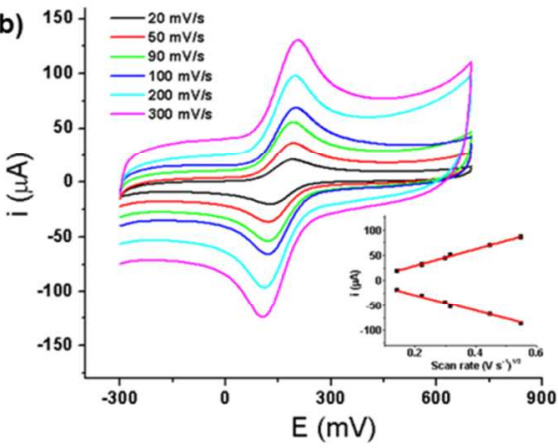

Figure 3. Electrochemical characterization (a) of the unmodified electrode (black line) and RG-SPCE (red line). Cyclic Voltammetries was performed monitoring a $\mathrm{Fe}(\mathrm{CN})_{6}{ }^{4-/ 3-}$ solution $\left(1 \mathrm{mM} \mathrm{K}_{4}\left[\mathrm{Fe}(\mathrm{CN})_{6}\right] / \mathrm{K}_{3}\left[\mathrm{Fe}(\mathrm{CN})_{6}\right]\right.$ in $\left.0.1 \mathrm{M} \mathrm{KCl}(\mathrm{pH} 6.50)\right)$ from $-300 \mathrm{mV}$ to $600 \mathrm{mV}$ at a scan rate of $50 \mathrm{mV} \mathrm{s}^{-1}$. (b) RG-SPCE under different scan rates of 20, 50, 90, 100, 200 and $300 \mathrm{mV} \mathrm{s}^{-1}$. Inset: anodic and cathodic currents vs the square root of corresponding scan rate.

One of the most important parameters in the use of modified electrodes is the optimum concentration of the employed nanomaterial. In our experiments, the working electrode was modified with the following concentrations of GO: $1 \mathrm{mg} \mathrm{mL}^{-1}$, $0.5 \mathrm{mg} \mathrm{mL}^{-1}, 0.1 \mathrm{mg} \mathrm{mL}^{-1}, 0.05 \mathrm{mg} \mathrm{mL}^{-1}$ and $0.01 \mathrm{mg} \mathrm{mL}^{-1}$. After the electrochemical reduction of the GO, each RG-SPCE was used for monitoring a $\mathrm{Fe}(\mathrm{CN})_{6}{ }^{4-/ 3-}$ solution. Fig. 4a shows that the use of graphene concentrations below $0.05 \mathrm{mg} \mathrm{mL}^{-1}$ does not show differences compared to the clean electrode and Fig. $4 \mathrm{~b}$ shows that the use of graphene concentrations above $0.1 \mathrm{mg} \mathrm{mL}^{-1}$ passivated the electrode.
Furthermore, an important goal is to obtain a homogeneous graphene layer onto electrode surface with a good electrochemical reversibility. These were evaluated by the ratio of the anodic and cathodic peak currents (Ipa/Ipc) as a function of the graphene concentration and related with the variation of the electroactive area (Fig. 4c). Fig. 4c also shows that the electrochemical reversibility and the electroactive area decay when the graphene concentration is higher than $0.1 \mathrm{mg} \mathrm{mL}^{-1}$.

These trends can be attributed to the graphene layers dispersion onto the electrode surface. When low concentrations of RGO are used, a homogeneous distribution of the graphene 
layers is achieved. While at high concentrations a nonthe $0.1 \mathrm{mg} \mathrm{mL}^{-1}$ graphene solution was used for optimal elechomogeneous distribution is generated causing a decrease in current and a loss of system reversibility. ${ }^{43}$ For these reasons,
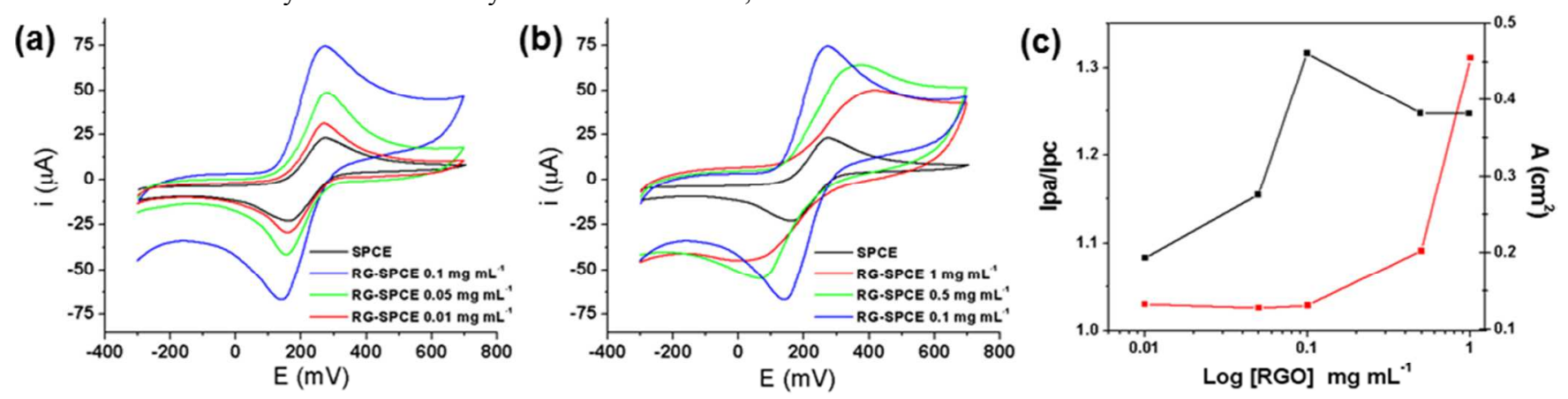

Figure 4. $\mathrm{CVs}$ of $\mathrm{Fe}(\mathrm{CN})_{6}^{4-/ 3-}$ solution obtained by RG-SPCE with graphene concentrations below to $0.1 \mathrm{mg} \mathrm{mL}^{-1}$ (a) to above $0.1 \mathrm{mg} \mathrm{mL}^{-1}$ (b). Evaluation of the graphene layer onto electrode surface, Ipc/Ipa (black curve to the left $\mathrm{Y}$ axis) and electroactive area (red curve to the right $\mathrm{Y}$ axis) versus $\mathrm{RG}$ concentrations (c).

Electrochemical study of EE2. The electrochemical behavior of EE2 was evaluated by Cyclic Voltammetry. A cyclic voltammogram for the potential range $0-1000 \mathrm{mV}$ of a 10 ppm EE2 in $10 \mathrm{mM}$ sulfuric acid solution (scan rate: $50 \mathrm{mV} \mathrm{s}$ ${ }^{1} ; \mathrm{T}=25 \pm 1{ }^{\circ} \mathrm{C}$ ) is shown in Fig. 5. The voltammogram exhibits a single irreversible anodic peak at $710 \mathrm{mV}$ corresponding to a two-electron transfer mechanism ${ }^{44}$ and showing that the oxidation of EE2 is an irreversible process in this reaction medium. As can be seen in Fig. 5a, the modification of the electrode surface with RG increased the oxidation peak current and hence, the sensitivity of the method.

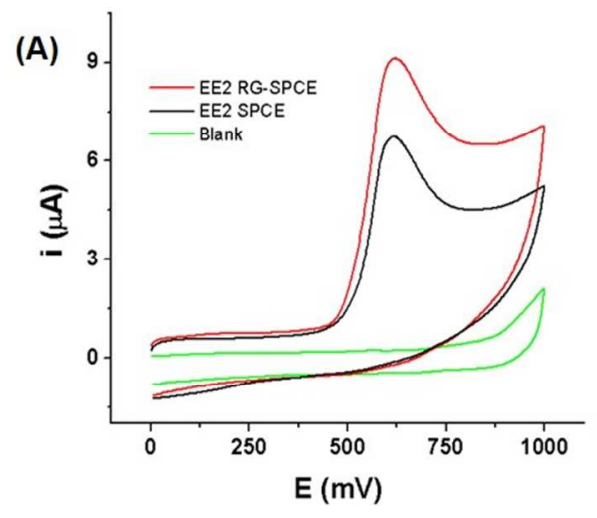

Fig. 5b shows the voltammograms obtained by SWV for 10 ppm EE2 solution in sulfuric acid using SPCE and RG-SPCE. Different instrumental variables were studied for the SWV measurement and the optimum conditions were: step $\mathrm{E}=4$ $\mathrm{mV}, \mathrm{SW}$ amplitude $=25 \mathrm{mV}$, SW frequency $=15 \mathrm{~Hz}$, samples per point $=256$, potential range $=300-1100 \mathrm{mV}$ and sensitivity $=1 \times 10-5 \mathrm{~A} \mathrm{~V}^{-1}$. Fig. $5 \mathrm{~b}$ shows that the use of RG on the working electrode surface increased the oxidation peak current for EE2 under the optimized experimental conditions.

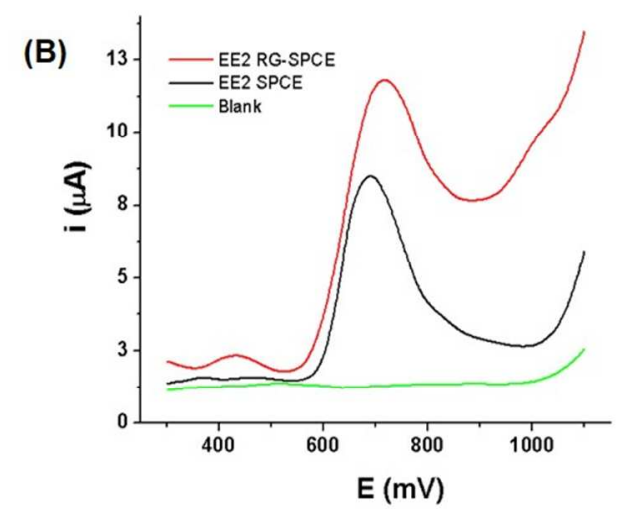

Figure 5. CVs (potential range $0-1000 \mathrm{mV}$ ) (A) and SWV voltammograms (potential range $=300-1100 \mathrm{mV}$ ) (B) for 10 ppm EE2 solution in $\mathrm{H}_{2} \mathrm{SO}_{4}(10 \mathrm{mM})$ using SPCE (black line) and RG-SPCE (red line); the green curves indicate the response of a blank solution.

Characterization of the modified paper microzone. In order to improve the efficiency of the immunocapture step, SNs were incorporated into paper microzones. The morphology of paper surface modified with SNs was studied by SEM. Fig. 6a shows a micrograph of a paper zone modified with SNs. The diameter of the nanoparticles was in a range of 50 $\mathrm{nm}$. The elemental composition was analyzed by EDS, the peak corresponding to $\mathrm{Si}$ at $1.74 \mathrm{keV}$ can be observed in the spectrum obtained (Fig. 6b). This proves that the modification with SNs was performed.

With the purpose of evaluating the amplification effect of SNs, we compared the obtained enzymatic signals for $1 \mathrm{mM}$
ADHP $+1 \mu \mathrm{L} \mathrm{mL}^{-1} \mathrm{H}_{2} \mathrm{O}_{2}$ solution with (a) HRP immobilized onto an unmodified paper microzone, (b) HRP immobilized onto a plasma treated paper microzone and (c) HRP immobilized onto a plasma treated paper microzone modified with SNs. Fig. $6 \mathrm{c}$ shows that the enzymatic response was higher when the paper was modified with SNs. Moreover, the signal amplification due to the SNs incorporation was demonstrated by carrying out the immunocapture and the SWV measurement of $120 \mathrm{ng} \mathrm{L}^{-1}$ of EE2 using a PAD with anti-EE2 antibodies immobilized and another PAD with SNs and anti-EE2 antibodies (Fig. 6d). 
(a)

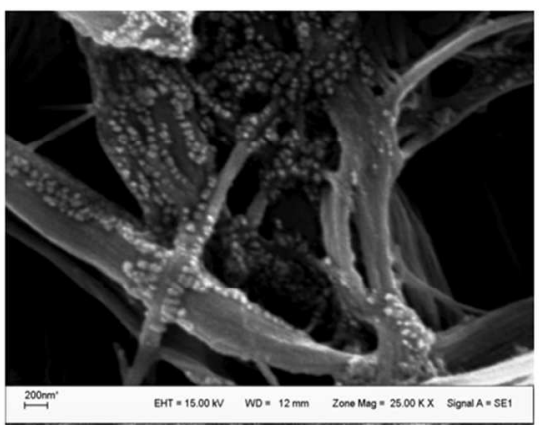

(c)

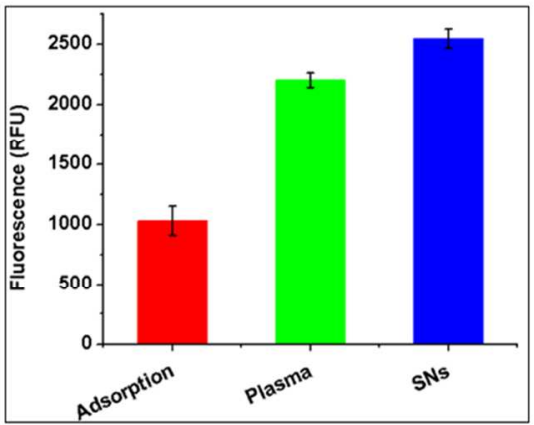

(b)

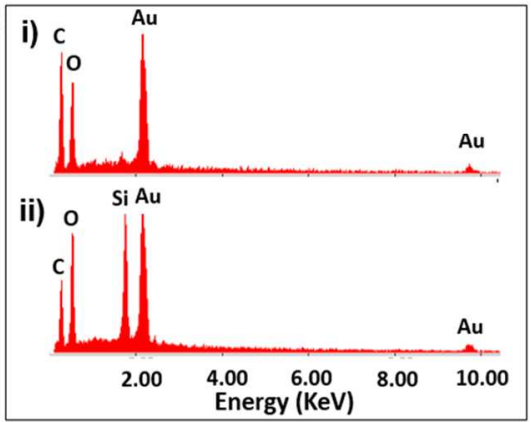

(d)

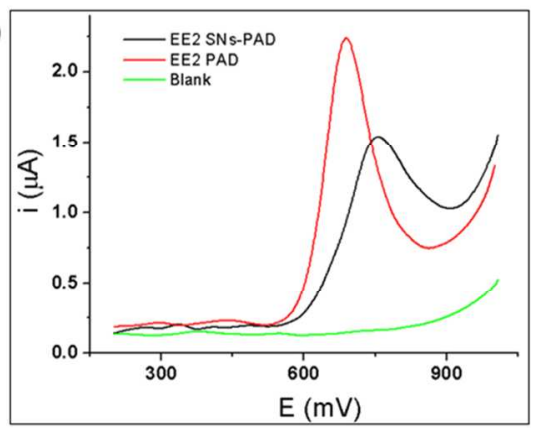

Figure 6. Paper microzone characterization. SEM image (a) and EDS spectrum (b) of paper modified with SNs. Evaluation of the amplification effect of SNs (c): Comparison of enzymatic signals for $1 \mathrm{mM} \mathrm{ADHP}+1 \mu \mathrm{L} \mathrm{mL}^{-1} \mathrm{H}_{2} \mathrm{O}_{2}$ solution with HRP immobilized onto an unmodified paper microzone, HRP immobilized onto a plasma treated paper microzone and HRP immobilized onto a plasma treated paper microzone modified with SNs. SWV voltammograms (d) (potential range $=300-1100 \mathrm{mV}$ ) for $10 \mathrm{ppm}$ EE2 solution in $\mathrm{H}_{2} \mathrm{SO}_{4}(10 \mathrm{mM})$ using SPCE (black line) and RG-SPCE (red line).

$\mathrm{H}_{2} \mathrm{SO}_{4}$ concentration. The concentration of the EE2 desorption solution is an important parameter that had to be optimized. For this purpose, the sulfuric acid concentration was studied in the range $5-20 \mathrm{mM}$. The current intensity increased when the $\mathrm{H}_{2} \mathrm{SO}_{4}$ concentration was increased until 10 $\mathrm{mM}$, then it remained relatively constant. Therefore, for the EE2 desorption solution $10 \mathrm{mM}$ sulfuric acid was selected as optimum concentration.

Matrix interference. The response of the proposed method in the presence of humic acid (HA) was evaluated as a simplified model for the determination of matrix effects. The obtained signal in the electrochemical determination was proportional to the amount of analyte bound in the immunocapture step. Although the interference mechanism is not fully understood, there may occur unspecific binding of the HA to the antibodies that can mimic the matrix effect. ${ }^{11}$ The effect of adding HA concentrations between 0.2 and $20 \mathrm{mg} \mathrm{L}^{-1}$ to EE2 standards studied is shown in Fig. 7. The selected concentration range for HA is in agreement with the mean values of dissolved organic carbon reported by Leech et al. ${ }^{45}$ Although there was a loss of sensitivity when the HA concentration increased above $10 \mathrm{mg} \mathrm{L}^{-1}$, no significant differences were found for this concentration of $\mathrm{HA}(\mathrm{P}<0.01, \mathrm{n}=5$, t-test).

EE2 quantitative determination and its application on water samples. Under the optimized conditions described above, a linear calibration curve to quantify the EE2 concentration in river water samples was obtained within the range 0 $120 \mathrm{ng} \mathrm{L}^{-1}$ using EE2 standard solutions. The linear regression equation obtained was $\Delta \mathrm{i}=4.38 \pm 8.28 \times$ CEE2 with a correlation coefficient $r=0.998$. The LOD was considered to be the concentration that gives a signal 3 times the standard deviation of the blank above its signal. For the electrochemical detection of EE2 the LOD was $0.1 \mathrm{ng} \mathrm{L}^{-1}$.

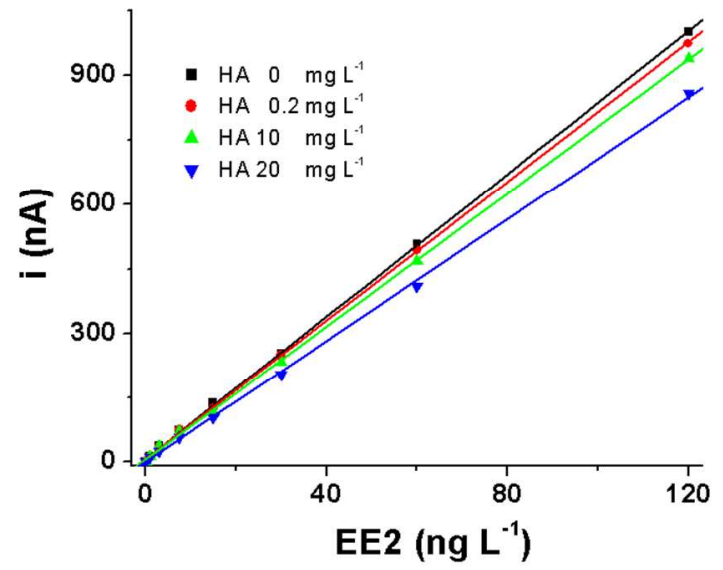

Figure 7. Influence of humic acid on EE2 calibration curves (EE2 standard solutions prepared with $0,0.2,10$ and $20 \mathrm{mg} \mathrm{L}^{-1}$ concentrations of humic acid).

Five natural and spiked water samples were analyzed to validate the reliability of the proposed method. After six measurements for each sample, the concentration of EE2 was determined and the results were listed in Table 1 . The recovery values obtained from spiked samples ranged from $97.5 \%$ to $103.7 \%$, with a relative standard deviation of less than $4.9 \%$, which indicated that the proposed method had a good accuracy and precision for quantitative detection of EE2 in water samples. The selectivity of the anti-EE2 antibodies was studied by Schneider et al. ${ }^{46}$ They evaluated cross-reactivity (CR) of the EE2 antiserum for estrone, estriol and the sulfate and glucuronide conjugated at ring position 17 , and only poor reactivities were observed $(\mathrm{CR}<0.5 \%)$. Concluding that the EE2 anti- 
serum exhibits excellent selectivity for EE2. Also, the intra and Inter-assay reproducibility was evaluated; the intra-assay precision was tested with six measurements for each EE2 control. These series of analyses were repeated for three consecutive days to estimate Inter-assay precision. The EE2 assay showed good precision; the RSD within-assay values were below $4.65 \%$ and the between-assay values below $5.2 \%$ (Table S-2, supplementary data). Also, it was clearly demonstrated that there were no matrix effects in EE2 determination in these real-world river water samples.

Table 1. Determination of EE2 in natural and spiked water sample

\begin{tabular}{lllll}
\hline \multirow{2}{*}{ Sample } & \multicolumn{2}{c}{ EE2 $\left(\mathrm{ng} \mathrm{L}^{-1}\right)$} & & \\
\cline { 2 - 3 } & Added & Found $^{\mathrm{a}}$ & RSD & Recovery (\%) \\
\hline River water (Potrero & - & $9.36 \pm 0.19$ & 2.03 & - \\
de los Funes, San & 5.0 & $14.69 \pm 0.28$ & 3.94 & 101 \\
Luis, Argentina) & 10.0 & $19.66 \pm 0.44$ & 2.24 & 103 \\
\hline River water (Trapiche, & - & $6.55 \pm 0.23$ & 3.51 & - \\
San Luis, Argentina) & 5.0 & $11.40 \pm 0.16$ & 1.40 & 97 \\
& 10.0 & $16.92 \pm 0.75$ & 4.43 & 104 \\
\hline River water (Volcán, & - & $3.91 \pm 0.13$ & 3.32 & - \\
San Luis, Argentina) & 5.0 & $8.81 \pm 0.26$ & 2.95 & 98 \\
& 10.0 & $13.68 \pm 0.27$ & 1.97 & 98 \\
\hline River water (San Luis, & - & $14.56 \pm 0.32$ & 2.20 & - \\
San Luis, Argentina) & 5.0 & $19.72 \pm 0.82$ & 4.16 & 103 \\
& 10.0 & $24.41 \pm 0.78$ & 3.20 & 99 \\
\hline Tap water (San Luis, & - & $1.64 \pm 0.07$ & 4.87 & - \\
Argentina) & 5.0 & $6.77 \pm 0.15$ & 2.22 & 103 \\
& 10.0 & $11.55 \pm 0.44$ & 3.80 & 99 \\
\hline
\end{tabular}

Mean of six determinations \pm S.D.

The proposed paper-based immunocapture assay was compared with a spectrophotometric immunoassay ${ }^{42}$ for the quantification of EE2 in river water samples and spiked water samples. These results were compared, and no significant differences were found $(\mathrm{P}<0.0, \mathrm{n}=6$, $\mathrm{t}$-test $)$ between both methods (Table S-3, supplementary data).

To the best of our knowledge, only a few articles have been published related to the quantitation of EE2 in water samples. Table 2 summarizes and compares the most relevant articles related to EE2 determination in water samples. ${ }^{11,30,42,47-51}$. Whereas just one of these articles have the advantage of improved sensitivity 30 , all mentioned manuscripts show complex sample processing steps, reiterated manual intervention and long incubation times, which do not meet usability requirements for point-of-care or point-of-incident diagnostic applications. In comparison to the studies in Table 2, we proposed a novel EPIA method in which the manual intervention is limited to simple steps that can be carried out by personnel without previous intensive training. It is important to highlight that the proposed electrochemical paper-based immunocapture assay is a novel methodology that shows an appropriate LOD for the quantification of EE2, not only for river water samples but also for other water samples. In comparison with the mentioned manuscripts in Table 2, the developed EPIA method is the only electrochemical paper-based immunocapture method reported to date which is prepared in a simple and inexpensive procedure. The simple equipment and straightforward technique required by our immunocapture sensor, the accuracy and the appropriate LOD and linear range achieved represent relevant parameters, particularly when the routine quantification of EE2 is considered. In addition to the above-mentioned features, our system was based on paper-based technology, which allows obtaining portable, easy-to-use, inexpensive and disposable device.

\section{CONCLUSION}

In this work, we described a novel EPIA method for the determination of EE2 in river water samples. We envision an EPIA platform to be a simple-to-use device in which manual intervention is limited to introducing the PAD into the sample, loading the PAD over the RG-SPCE and hitting the start button for the electrochemical measurement. The developed method combines the specificity of the immunochemical binding and the inherent sensitivity of OSWV with the advantage of the use of paper-based analytical devices, providing sensitivity, ease-of-use, low cost and short assay times. The incorporation of SNs as bioaffinity support increased the active area of the PAD. Furthermore, the modification of the working electrode with graphene improved the sensitivity of the method. The proposed EPIA can also serve as a general-purpose immunoassay platform for point-of-care and point-ofincidence applications providing a revolutionary methodology with possible use for monitoring other drugs and emerging pollutants in environmental samples.

Table 2. Comparison of available methods for determination of EE2

\begin{tabular}{|c|c|c|c|}
\hline Method & $\begin{array}{l}\text { LOD } \\
\left(\text { ng L L }^{-1}\right)\end{array}$ & $\begin{array}{l}\text { Linear range } \\
\left(\text { ng L L }^{-1}\right)\end{array}$ & Reference \\
\hline ELISA & 20 & $20-1 \times 10^{4}$ & [11] \\
\hline $\begin{array}{l}\text { Solid-phase extraction coupled with liquid } \\
\text { chromatography tandem mass spectrome- } \\
\text { try }\end{array}$ & 7 & $7-100$ & [47] \\
\hline $\begin{array}{l}\text { Competitive homogeneous energy transfer } \\
\text { immunoassay }\end{array}$ & 10 & $40-2 \times 10^{5}$ & [48] \\
\hline $\begin{array}{l}\text { Bioseparation procedure coupled with } \\
\text { electrochemical detection }\end{array}$ & 0.01 & $0.02-70$ & [30] \\
\hline Chemiluminescence ELISA & 0.2 & $0.8-100$ & [42] \\
\hline $\begin{array}{l}\text { Electrochemical detection based on mag- } \\
\text { netic nanoparticles }\end{array}$ & 10 & $10-1 \times 10^{3}$ & [49] \\
\hline $\begin{array}{l}\text { Solid-phase microextraction coupled to } \\
\text { gas chromatography-mass spectrometry }\end{array}$ & 10 & $27-1.95 \times 10^{5}$ & [50] \\
\hline Solid-phase extraction coupled HPLC-MS & 0.2 & $1-100$ & [51] \\
\hline Paper-based immunocapture assay (EPIA) & 0.1 & $0.5-120$ & $\begin{array}{l}\text { This } \\
\text { paper }\end{array}$ \\
\hline
\end{tabular}

\section{ASSOCIATED CONTENT}

\section{Supporting Information}

Additional information as noted in the text.

Supporting Information for Publication.docx. Comparison between the proposed EPIA and a spectrophotometric immunoassay. Time required for the quantification of EE2 by the developed EPIA. 


\section{AUTHOR INFORMATION}

\section{Corresponding Author}

*E-mail: messina@unsl.edu.ar. (Tel.)+54-266-4425385; (Fax) +54-266-443-0224.

INQUISAL, Departamento de Química. Universidad Nacional de San Luis, CONICET. Chacabuco 917. D5700BWS. San Luis, Argentina

\section{ACKNOWLEDGMENT}

The authors wish to thank the financial support from the Universidad Nacional de San Luis (PROICO-1512-22/Q232), the Agencia Nacional de Promocion Cientifica y Tecnológica, the Consejo Nacional de Investigaciones Cientificas y Tecnicas (CONICET) (PICT-2015-2246, PICT 2015-3526, PICT-2014-1184, PICT2013-3092), Instituto de Nanosistemas, Universidad Nacional de General San Martín, Argentina and BAM Federal Institute for Materials Research and Testing, Berlin, Germany, for providing the immunoreagents and for helpful discussions.

\section{REFERENCES}

(1) Rodil, R.; Quintana, J. B.; Concha-Graña, E.; López-Mahía, P.; Muniategui-Lorenzo, S.; Prada-Rodríguez, D. Chemosphere 2012, 86, 1040-1049.

(2) Rosal, R.; Rodríguez, A.; Perdigón-Melón, J. A.; Petre, A.; García-Calvo, E.; Gómez, M. J.; Agüera, A.; Fernández-Alba A. R. Water Res. 2010, 44, 578-588.

(3) Tijani, J. O.; Fatoba, O. O.; Babajide, O. O.; Petrik, L. F. Environ. Chem. Lett. 2016, 14, 27-49.

(4) Garmshausen, J.; Kloas, W.; Hoffmann, F. Comp. Biochem. Physiol., Part C 2015, 171, 34-40.

(5) Aris, A. Z.; Shamsuddin, A. S.; Praveena, S. M. Environ. Int. 2014, 69, 104-119.

(6) Schwab, B. W.; Hayes, E. P.; Fiori, J. M.; Mastrocco, F. J.; Roden, N. M.; Cragin, D.; Meyerhoff, R. D.; D’Aco, V. J.; Anderson, P. D. Regul. Toxicol. Pharmacol. 2005, 42, 296-312.

(7) Safe S. H. Environ. Health Perspect. 2000, 108(6), 487-493.

(8) Rocha, S.; Domingues, V. F.; Pinho, C.; Fernandes, V. C.; Delerue-Matos, C.; Gameiro, P.; Mansilha, C. Bull. Environ. Contam. Toxicol. 2013, 90, 73-78.

(9) Esperanza, M.; Suidan, M. T.; Nishimura, F.; Wang, Z. M.; Sorial, G. A.; Zaffiro, A.; McCauley, P.; Brenner, R.; Sayles, G. Environ. Sci. Technol. 2004, 38, 3028-3035.

(10) Gañán, J.; Morante-Zarcero, S.; Pérez-Quintanilla, D.; Sierra, I. Mater. Lett. 2014, 132, 19-22.

(11) Silva, C. P.; Lima, D. L. D.; Schneider, R. J.; Otero, M.; Esteves, V. I. J. Environ. Manage. 2013, 124, 121-127.

(12) Martínez, N. A.; Schneider, R. J.; Messina, G. A.; Raba, J. Biosens. Bioelectron. 2010, 25, 1376-1381.

(13) Martinez, A. W.; Phillips, S. T.; Butte, M. J.; Whitesides, G. M., Angew. Chem. Int. Edit. 2007, 46, 1318-1320.

(14) Cate, D. M.; Adkins, J. A.; Mettakoonpitak, J.; Henry C. S. Anal. Chem. 2015, 87, 19-41.

(15) Martinez, A.W.; Phillips, S. T.; Whitesides, G. M. Anal. Chem. 2010, 82, 3-10.

(16) Wang, S.; Ge, L.; Song, X.; Yan, M.; Ge, S.; Yu, J.; Zeng, F. Analyst 2012, 137, 3821-3827.

(17) Zang, D.; Ge, L.; Yan, M.; Song, X.; Yu, J. Chem. Commun. 2012, 48, 4683-4685.

(18) Glavan, A. C.; Christodouleas, D. C.; Mosadegh, B.; Yu, H. D.; Smith, B. S.; Lessing, J.; Fernandez-Abedul, M. T.; Whitesides, G. M. Anal. Chem. 2014, 86, 11999-12007.

(19) Hossain, S. M. Z.; Luckham, R. E.; McFadden, M. J.; Brennan, J. D. Anal. Chem. 2009, 81, 9055-9064.
(20) Wang, L. B.; Chen, W.; Xu, D. H.; Shim, B. S.; Zhu, Y. Y.; Sun, F. X.; Liu, L. Q.; Peng, C. F.; Jin, Z. Y.; Xu, C. L.; Kotov, N. A. Nano Lett. 2009, 9, 4147-4152.

(21) Apilux, A.; Dungchai, W.; Siangproh, W.; Praphairaksit, N.; Henry, C. S.; Chailapakul, O. Anal. Chem. 2010, 82, 1727-1732.

(22) Dungchai, W.; Chailapakul, O.; Henry, C. S. Anal. Chem. 2009, 81, 5821-5826.

(23) Cheng, C.; Martinez, A. W.; Gong, J.; Mace, C. R.; Phillips, S. T.; Carrilho, E.; Mirica, K. A.; Whitesides, G. M. Angew. Chem. Int. Ed. 2010, 49, $4771-4774$.

(24) Zhao, M.; Li, H.; Liu, W.; Guo, Y.; Chu, W. Biosens. Bioelectron. 2016, 79, 581-588.

(25) Medawar, V.; Messina, G. A.; Fernández-Baldo, M.; Raba, J.; Pereira, S. V. Microchem. J. 2017, 130, 436-441.

(26) Kang, T.; Lee, J. H.; Oh, S. G. J. Ind. Eng. Chem. 2017, 46, 289-297.

(27) Bapat, G.; Labade, C.; Chaudhari, A.; Zinjarde, S. Adv. Colloid Interface Sci. 2016, 237, 1-14.

(28) Ghoneim, E. M.; El-Desoky, H. S.; Ghoneim, M. M. J. Pharm. Biomed. Anal. 2006, 40, 255-261.

(29) Li, C. Bioelectrochemistry 2007, 70, 263-268.

(30) Martínez, N. A.; Pereira, S. V.; Bertolino, F. A.; Schneider, R. J.; Messina, G. A.; Raba, J. Anal. Chim. Acta 2012, 723, 27-32.

(31) Chen, A.; Chatterjee S. Chem. Soc. Rev. 2013, 42, 5425-5438.

(32) Maduraiveeran, G.; Jin, W. Trends Environ. Anal. Chem. 2017, 13, 10-23.

(33) Goyal, R. N.; Chatterjee, S.; Rana, A. R. S. Carbon. 2010, 48, 4136-4144.

(34) Shao, Y.; Wang, J.; Wu, H.; Liu, J.; Aksay, I. A.; Lin, Y. Electroanalysis 2010, 22(10), $1027-1036$.

(35) Geim, A. K.; Novoselov, K. S. Nat. Mater. 2007, 6, 183 - 191

(36) Alwarappan, S.; Erdem, A.; Liu, C.; Li, C. Z. J. Phys. Chem. C 2009, 113, 8853-8857.

(37) Chung, C.; Kim, Y. K.; Shin, D.; Ryoo, S. R.; Hong, B.H.; Min, D.H. Acc. Chem. Res. 2013, 46, 2211-2224.

(38) Ngo, Y. H.; Li, D.; Simon, G. P.; Garnier, G. Adv. Colloid Interface Sci. 2011, 163, 23-38.

(39) Hintemann T., Schneider C., Schöler H.F., Schneider R.J. Water Res. 2006, 40, 2287-2294.

(40) Hummers W. S.; Offeman R. E. J. Am. Chem. Soc. 1958, 80, 1339.

(41) Toh, S. Y.; Loh, K. S.; Kamarudin, S. K.; Daud, W. R. W. Electrochim. Acta 2016, 199, 194-203.

(42) Schneider, C.; Schöler, H. F.; Schneider, R. J. Anal. Chim. Acta 2005, 551, 92-97.

(43) Silva, M. M. S.; Dias, A. C. M. S.; Silva, B. V. M.; GomesFilho, S. L. R.; Kubota, L. T.; Goulart, M. O. F.; Dutra, R. F. J Chem. Technol. Biotechnol. 2015, 90, 194-200.

(44) Pavinatto, A.; Mercante, L. A.; Leandro, C. S.; Mattoso, L. H. C.; Correa, D. S. J. Electroanal. Chem. 2015, 755, 215-220.

(45) Leech, D. M.; Snyder, M. T.; Wetzel, R. G. Sci. Total Environ. 2009, 407, 2087-2092.

(46) Schneider, C.; Schöler, H. F.; Schneider R. J. Steroids 2004, $69,245-253$

(47) Viglino, L.; Aboulfadl, K.; Prévost, M.; Sauvé, S. Talanta 2008, 76, 1088-1096.

(48) Coille, I.; Reder, S.; Bucher, S.; Gauglitz, G. Biomol. Eng. 2002, 18, 273-280.

(49) Kanso, H.; Barthelmebs, L., Inguimbert, N.; Noguer, T. Anal. Chem. 2013, 85, 2397-2404.

(50) Braun, P.; Moeder, M.; Schrader, S.; Popp, P.; Kuschk, P.; Engewald, W. J. Chromatogr. A 2003, 988, 41-51.

(51) Avar, P.; Zrínyi, Z.; Maász, G.; Takátsy, A.; Lovas, S.; Tóth, L. G.; Pirger, Z. Environ. Sci. Pollut. Res. 2016, 23, 11630-11638. 


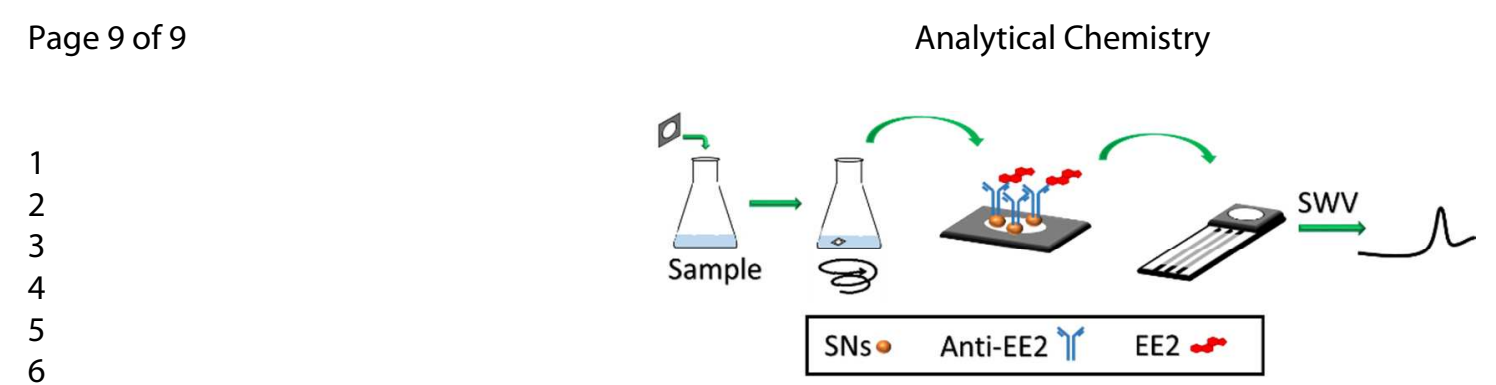

